\title{
Drafting force measurement: A New method to Optimize Drafting Process
}

\author{
${ }^{\text {a }}$ Qasim Siddiqui*, a Abdul Malik Rehan abbassi, ${ }^{\text {b }}$ Awais Naeem \\ a: Department of Textile Engineering, BUITEMS Quetta, Pakistan \\ b: Laboratory of Eco - Textiles, Jiangnan Univwerity, Wuxi, China
}

Corresponding Author: qasim.siddiqui@buitms.edu.pk

\begin{abstract}
This study is focused on the optimization of drafting process through measuring drafting force and short term irregularities of fiber strand. Drafting force is the instinctive factor initiated by the frictional forces between slow moving and fast moving fibers during attenuation. Drafting force can be a good source of information regarding dynamic fiber behavior and reflects combined effect of multiple fiber and process parameters, for a particular materiel. The interaction between break draft and drafting force and how these in turn affect the irregularity of sliver has been analyzed by utilizing data from online drafting force device. The results showed that dynamic drafting force increases with the increase in break draft around $\mathbf{1 . 4}$ and then decreases with further increase in break draft. Short term sliver irregularity decreases up to 1.4 break draft and then increases as break draft increases. Furthermore, the region where drafting force reaches its maximum corresponds to the minimum sliver unevenness. Optimum break draft setting can be achieved at a point where the drafting force reached its maximum along with minimum short term sliver irregularity.
\end{abstract}

Keywords- Break draft, Dynamic drafting force, Short term sliver Irregularity

Date Received 20 May 2019

Date Accepted 30 June 2019

Date Published 5 July 2019

\section{INTRODUCTION}

A Defective sliver production for one minute on a finisher draw frame, for example, is bound to spoil several hundred meters of fabric in the knitting or weaving mill. Draw frame is regarded as the last fault correction point in the spinning preparation chain, therefore, its settings, especially break draft has a significant role to play towards short term evenness of output strand. To understand the fiber dynamic behavior during their attenuation, break draft is one of the most important factor to be considered. Continuing the early work by Vasilieff, Grishin establish a theoretical equation for calculating the sectional drafts in the roller drafting system in 1945. The Grishin's formula was based on the total draft, the roller gauge setting, the fiber length and its variation. However, in roller drafting, dynamic fiber behavior is also influenced by many factors such as type of fiber, fiber fineness, fiber crimps and fiber hooks. It will be quite difficult to develop an equation which can apprehend all factors affecting fiber movements during their attenuation. The alternative approach to hack into the fiber behavior during drafting is through drafting force, which reflects overall velocity-friction characteristics of fibers.

Drafting force is the direct and intuitive factor resulting in fiber motion in a drafting zone [1]. The way a fiber behaves in the drafting process depends on the frictional force and, more specifically, on the variation of frictional force in the surrounding fibers [2]. In 1947, Martindale [3] first set up an apparatus for measuring the drafting force of cotton slivers, and he studied the influence of drafting ratio, roller gauge, fiber weight, spinning procedure, and fiber orientation. Others used the technique of drafting force when choosing a suitable draft ratio for break draft in spinning to obtain the best output evenness [3-7].

Recently Z. Zhang and C. Yu [8], has developed online drafting force measuring device, installed on the front drafting zone of industrial scale draw frame. The result reported in $\mathrm{Z}$. Zhang study demonstrates that the draft settings have a considerable effect on the drafting force, and the break draft ratio has a distinct relation to sliver irregularity. Furthermore, it lacks to separate the effects of the break draft from the main draft because the drafting force measured only in the front drafting zone.

In this study we have assessed the drafting force and unevenness of cotton sliver to determine the optimum break draft ratio for achieving minimum sliver irregularity, both at back and front drafting zone.

\section{MATERIALS AND METHODS}

Carded sliver (linear density 3700 tex) has been prepared from $100 \%$ cotton fiber. Fiber properties were measured with High Volume Instrumentation (Uster HVI 1000) and Advanced Fiber Information System (AFIS Pro-2), and shown at Table-1. The card slivers were further processed on DHU draw frame under different break draft ratios. Meanwhile, drafting force values were collected by dynamic drafting force measurement equipment [8], which has been developed earlier, installed in the back draft zone of the DHU draw frame. 3 by 3 drafting rollers set comprising of two drafting zones has been employed with back roller speed of $44 \mathrm{rpm}$. The back ratch and main ratch were fixed at 44 and $40 \mathrm{~mm}$ respectively. In order to get the 
effect of the break draft on sliver short term irregularity, total draft was kept constant at 4 , while break drafts changed, namely $1.1,1.2,1.3,1.4,1.5,1.6$ and 1.7. Furthermore, to analyze the effect of the break draft on drafting force at the main drafting zone, card sliver of linear density 4000 tex was drafted and drafting force measured at front zone.

After conditioning for $24 \mathrm{~h}$ at $20 \mathrm{o} \mathrm{C}$ and $65 \% \mathrm{RH}$, slivers samples were tested for irregularity on the unevenness tester (Changling YG135) at the speeds of $25 \mathrm{~m} / \mathrm{min}$, for $5 \mathrm{~min}$ according to ASTM 1425.

TABLE 1

Fiber Properties

\begin{tabular}{|l|l|l|l|l|l|l|}
\hline $\begin{array}{l}\text { Fiber } \\
\text { Nep } \\
{[\mathrm{Cnt} / \mathrm{g}]}\end{array}$ & $\begin{array}{l}\text { Fiber } \\
\text { Mean } \\
\text { Lengt } \\
\mathrm{h} \\
{[\mathrm{mm}]} \\
\mathrm{w})\end{array}$ & $\begin{array}{l}\text { Length } \\
\mathrm{CV} \\
{[\%](\mathrm{w})}\end{array}$ & $\begin{array}{l}\text { SFC } \\
>12.7 \\
\mathrm{~mm} \\
{[\%]}\end{array}$ & $\begin{array}{l}\text { UQL } \\
{[\mathrm{mm}]} \\
(\mathrm{w})\end{array}$ & $\begin{array}{l}\text { Fineness } \\
{[\mathrm{mtex}]}\end{array}$ & $\begin{array}{l}\text { Maturity } \\
\text { Ratio }\end{array}$ \\
\hline 274 & 24.8 & 34.5 & 8.8 & $\begin{array}{l}30.2 \\
2\end{array}$ & 155 & 0.89 \\
\hline
\end{tabular}

Note: w - by weight ; SFC - short fiber content; SL - span length.

\section{RESULTS AND DISCUSSION}

The curve in the Figure-1 shows that increase in the break draft ratio results in increase in drafting force up to a point between 1.3 to 1.4 and this area can be categorized as a peak region. This rise of drafting force is because of fiber straightening and hooks removal. The low relative speed between middle and back rollers results in higher fiber-to-fiber friction and reflected in the form of increased drafting force. As the draft ratio further increases, the speed of front roller relative to the back roller is considerably greater. At this point the dynamic friction between fibers is predominant and the shearing force more readily overcomes the inter-fiber friction, so fibers begin to slide more easily, resulting in decline of drafting force.

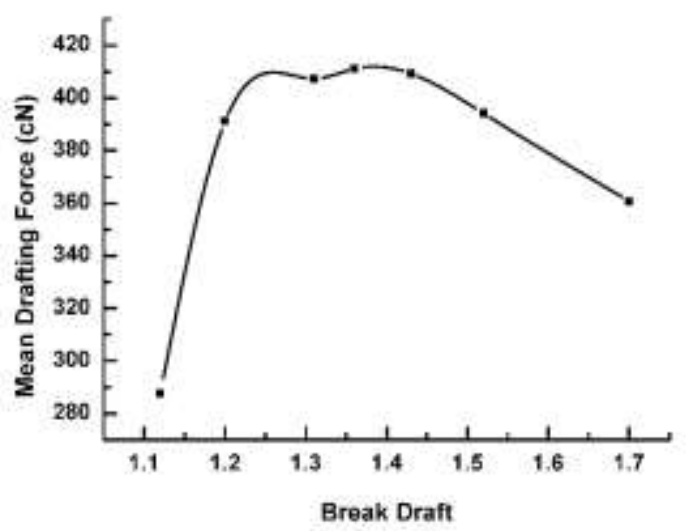

Figure-1 Effect of Break draft on Drafting force and Sliver Unevenness

It is acclaimed that the dynamic friction coefficient of fibers is usually lower than the static friction coefficient, and the difference contributes to the "stick-slip" motion of fibers which causes the drafting waves in roller drafting [9]. Figure-2 depicts the relation between break draft and sliver irregularity. It can be seen that the sliver irregularity drops up to break draft 1.4 but then the unevenness increased with further increases in break draft. The better short term unevenness relative to the break draft is attributed to the better opening and equalizing of small fiber bundles. By comparing figures- 1 and 2 we may conclude that the minimum sliver irregularity near 1.4 break draft correspond to the peak region of drafting force. This break draft, where sliver irregularity reached its minimum and drafting force has reached its maximum, can be used to optimize the break draft.

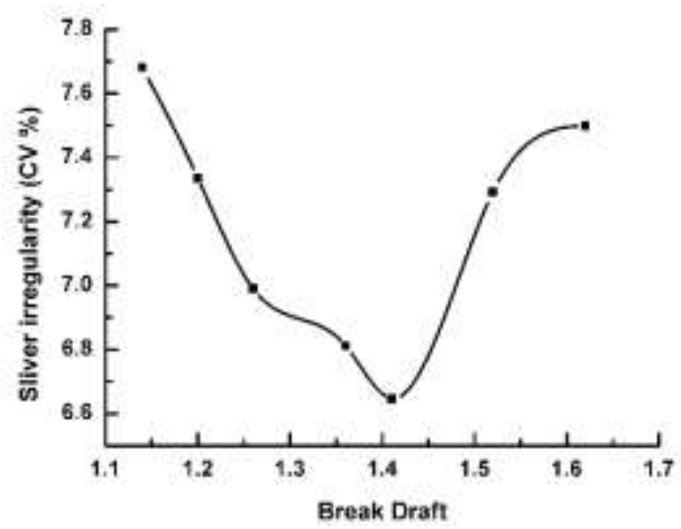

Figure 2 Effect of Break draft short term sliver unevenness

To examine the effect of break draft on drafting force in main draft, another experiment was designed. Break draft 1.24 and 1.35 has been selected (both at peak region of drafting force), and the draft at front zone was changed from 1 to 5. Meanwhile, the drafting force was measured at front draft zone. In figure 3 the peak region of drafting force is clearly seen around 1.5. As compared to figure 1 , the shift of peak point is due to the difference of draft zone; here the sliver already drafted in the break draft zone, also the higher drafting force is due to the higher weight of input sliver (4000 tex). The difference in magnitude of drafting force between break draft 1.24 and 1.35 can also be seen. The sliver with break draft 1.35 shown higher drafting force in the front zone as compare to break draft 1.24. Furthermore, as the draft increased from 1.5 to onwards the drafting force gradually decreases, which is due to relatively high speed difference between the middle roller and front roller. 


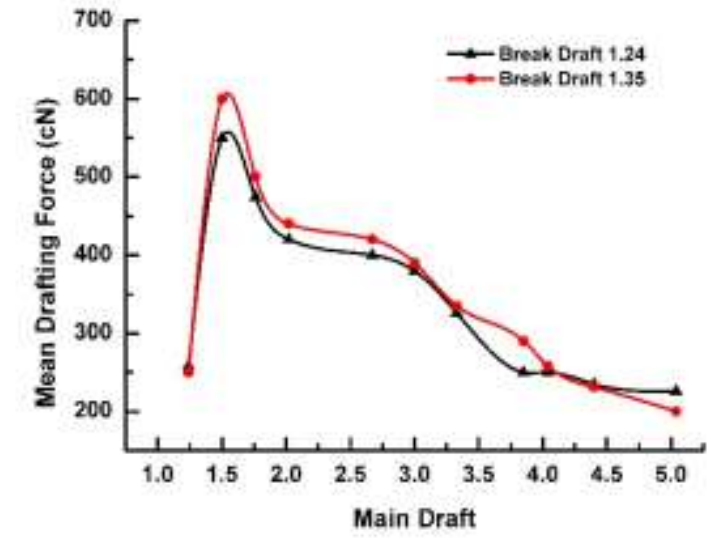

Figure 3 Effect of draft in front drafting zone with different break drafts.

\section{CONCLUSION}

The study of interaction between drafting force and break draft helps to provide better understanding of fiber behavior during their attenuation. The results obtained showed that it is possible to optimize break draft settings with the help of drafting force. Therefore, better short term linear density of cotton sliver may be achieved with the optimized break draft. It is inferred that the drafting force is dependent on break draft, and there exists a peak region in which drafting force reaches its maximum point. In short, high values of drafting force correspond to better sliver unevenness can be utilized for break draft setting.

\section{REFERENCES}

[1] D. Burnett. (1959, Aug.). A Theory of roller Drafting. Journal of the Textile Institute Transactions. [Online]. 50(4), pp.297-310. Available:https://www.tandfonline.com/doi/abs/10.1080/194470259086 60143

[2] Qian Lin, William Oxenham \& Chongwen Yu. (2011, Mar.). A study of the drafting force in roller drafting and its influence on sliver irregularity. The Journal of Textile Institute. [Online]. 102(11), pp. 994-100. Available: https://www.tandfonline.com/doi/full/10.1080/00405000.2010.529284

[3] J. G. Martindale. (1945, Dec.). A new method of measuring the irregularity of yarns with some observations on the origin of irregularities in worsted slivers and yarns. Journal of the Textile Institute Transactions. [Online]. 36(3), pp.35-47. Available: https://www.tandfonline.com/doi/abs/10.1080/19447024508659383

[4] Hannah, M. (1950, Jan.). The theory of high drafting. Journal of the Textile Institute Transactions. [Online]. 41(3), pp.57-123. Available: https://www.tandfonline.com/doi/abs/10.1080/19447025008659841

[5] Olsen, J. S. (1974, Nov.). Measurement of Sliver Drafting Forces. Textile Research Journal. [Online]. 44(11), pp. 852-855. Available: https://www.journals.sagepub.com/doi/pdf/10.1177/0040517574044011 05

[6] Backer, H. R. P. a. S. (1967, Aug.). The Dynamics of Roller Drafting : Part I : Drafting Force Measurement. Textile Research Journal. [Online]. $37(8), \quad$ pp. $559-563 . \quad$ Available: https://www.journals.sagepub.com/doi/pdf/10.1177/0040517567037008 07

[7] Su, C. -I.; Lo, K. -J.; Lee, J. -Y. (1998, Aug.). Drafting Force of Fine Denier Polyester Fibers. Textile Research Journal. [Online]. 68(8). pp. 559-563.

Available: https://www.journals.sagepub.com/doi/pdf/10.1177/0040517598068008 03
[8] Zhiliang Zhang \& Chongwen Yu. (2012, Jun.). Study on drafting force and sliver irregularity on drawing frame. The Journal of The Textile Institute. [Online]. 103(3), pp. 341-347. Available: https://www.tandfonline.com/doi/full/10.1080/00405000.2011.578356

[9] Chen, G.; Wang, Y. (2010, Apr.). Effect of High-frequency Vibration on the Drawing Behavior of Staple Fiber Strands. Textile Research Journal. [Online]. $\quad 80(17), \quad$ pp. 1777-1783. Available: https://www.journals.sagepub.com/doi/pdf/10.1177/0040517510369400

[10] Dogu, I. (1971, Jun.). A Study of the Theory of Drafting Force in a RollerDrafting Process. Textile Research Journal. [Online]. 41(6), pp. 534-545. Available: https://www.doi.org/10.1177/004051757104100609 